Open Access

\title{
Protocol for systematic review of evidence on the determinants and influence of early glycaemic control in childhood-onset type 1 diabetes
}

Veena Mazarello Paes ${ }^{1,2^{*}}$, Dimitrios Charalampopoulos ${ }^{1}$, Amal R. Khanolkar ${ }^{1,3}$, David Taylor-Robinson ${ }^{1,4}$, Russell Viner ${ }^{1}$, Julie Edge ${ }^{5}$, Terence Stephenson ${ }^{1}$ and Rakesh Amin ${ }^{1}$

\begin{abstract}
Background: Landmark studies in adult-onset type 1 diabetes (T1D) populations indicate that improved glycaemic control through use of intensive insulin therapy is strongly associated with reduced risk for the development of diabetes-related complications and mortality in later years. However, it is unclear whether these associations can be extrapolated to childhood-onset T1D, given the influence of other important biological and psychosocial determinants of glycaemic control, particularly during adolescence. The aims of the review are (1) to investigate the impact of early glycaemic control (within the first 2 years after diagnosis) on subsequent glycaemic trends and risk of complications during the life course of childhood-onset T1D and (2) to identify the predictors of early glycaemic control in children and young people ( $0-25$ years).
\end{abstract}

Methods: The methods used in this study are systematic identification, review and mapping of quantitative (intervention and observational) and qualitative literature; assessing the effect and predictors of early glycaemic control in T1D (diagnosed $\leq 18$ years) on risk or prevalence of later complications. An iterated search strategy, with no language or period restrictions, was applied to identify studies from six electronic databases. This will be supplemented by hand-searching (reference lists and contacting authors of studies meeting the inclusion criteria). Studies assessing glycaemic control within the first 2 years of diagnosis in children (at baseline) will be quality-assessed against predefined criteria and mapped descriptively to future health outcomes. Extracted data will be analysed and synthesised using narrative and forest plots or harvest plots for quantitative evidence and thematic analyses for qualitative studies. To get a deeper understanding of the predictors of early glycaemic control in reducing complications in childhood and adult life, we will integrate qualitative and quantitative evidence using mixed methods or parallel synthesis approach.

Discussion: These linked reviews will be the first to systematically investigate the effects of early glycaemic control and integrate both the quantitative and qualitative evidence on predictors of early glycaemic control in childhood-onset T1D in reducing future diabetes complications. This will help identify and map current research and inform development of effective future interventions.

Systematic review registration: PROSPERO CRD42015024546

\footnotetext{
*Correspondence: veena.paes.14@ucl.ac.uk

1 Institute of Child Health, University College London, London, UK

${ }^{2}$ Institute of Public Health, University of Cambridge, Cambridge, UK

Full list of author information is available at the end of the article
}

C Biomed Central (c) 2015 Mazarello Paes et al. Open Access This article is distributed under the terms of the Creative Commons Attribution 4.0 International License (http://creativecommons.org/licenses/by/4.0/), which permits unrestricted use, distribution, and reproduction in any medium, provided you give appropriate credit to the original author(s) and the source, provide a link to the Creative Commons license, and indicate if changes were made. The Creative Commons Public Domain Dedication waiver (http://creativecommons.org/publicdomain/zero/1.0/) applies to the data made available in this article, unless otherwise stated. 


\section{Background}

Recent studies indicate a reduction of life expectancy by over a decade, in people diagnosed with type 1 diabetes (T1D) [1-3]. Given the duration of glycaemic exposure, the risk for diabetes-related vascular diseases is likely to be greater in childhood-onset compared to adult-onset T1D [3-6]. The burden of T1D greatly impacts upon the quality of life of children and their families [7, 8]. These poor outcomes have been highlighted by health policy advisers [9] and are of relevance given the increasing worldwide incidence of childhood T1D [10-14], and in those aged under 5 years, in whom both prognosis and burden of disease are likely to be even worse [15-18]. The strongest modifiable predictor of complications in T1D patients is glycaemic control, which is measured as haemoglobin $A 1_{c}$ levels $\left(H b A 1_{c}\right)$ [19-22]. Use of intensive insulin therapy in young children is associated with better glycaemic control (i.e. lower $\mathrm{HbA1}_{\mathrm{c}}$ levels) [23].

Results from a recent systematic review of 18 clinical trials (with a total of 2254 T1D participants and a mean follow-up duration across studies varying between 1 and 25 years) showed that targeting intensive glycaemic control (four or more insulin injections per day or insulin pump therapy) did not improve all-cause mortality, but it reduced the relative risk of the composite macrovascular outcomes (0.63; confidence interval (CI) 0.41 to 0.96 ; $P=0.03)$ and diabetic nephropathy $(0.37$; CI 0.27 to 0.50 ; $P<0.00001)$, when compared to management with conventional insulin regimens (i.e. three or less insulin injections per day) [24]. However, the review could not assess the effect of targeting intensive glycaemic control on patients younger than 18 years and no macrovascular or microvascular outcomes were reported in the four small trials (sample sizes between 14 and 34), three of which included newly diagnosed T1D patients under 18 years, probably due to the short follow-up period of up to 1.5 years [25-28].

An updated Cochrane review with 12 trials (with a mean follow-up duration across studies varying between 1 and 6.5 years) concluded that tight glycaemic control (compared to less intense treatment targets) was beneficial in younger patients (age not specified), at early stages of disease (retinopathy: RR 0.27 (95\% CI 0.18 to 0.42); $P<0.00001$; nephropathy: RR 0.56 (95 \% CI 0.46 to 0.68 ); $P<0.00001$; neuropathy: RR 0.35 (95\% CI 0.23 to 0.53$) ; P<0.00001$ ) [29]. However, this review contained just one trial in young children aged 6-15 years with diabetes duration of 1-2 years [30], and most of the other included trials were conducted in the 1980s, when use of insulin pump therapy was less widespread.

Also, evidence from landmark studies indicates that improved glycaemic control in T1D through use of intensive insulin therapy is strongly associated with reduced complications risk and mortality [19, 31, 32]. Results from the Diabetes Control and Complications Trial (DCCT), a multicenter, randomised controlled clinical trial of 1441 people (including 195 adolescents) with T1D (1983-1993), provided evidence that early intensive glycaemic control conferred a significant reduction in risk of microvascular and macrovascular complications compared to conventional treatment, an effect which continued in subsequent years even after equalisation of metabolic control [21, 31, $33,34]$. Importantly, reduced mortality was also observed with the use of early intensive versus conventional insulin therapy use (43 deaths versus 64 deaths respectively among 1429 participants; hazard ratio 0.67 (95 \% CI 0.46-0.99)) after 27 years from entry into the trial [31]. All-cause mortality was significantly higher among those with higher mean $\mathrm{HbA1}_{\mathrm{c}}$ levels (hazard ratio $(\mathrm{HR})=1.56$ (95\% CI $1.35-1.81$ per $10 \%$ relative increase in $\mathrm{HbAl}_{\mathrm{c}}$ ); $P<0.001)$ and with renal disease $(\mathrm{HR}=8.51(95 \% \mathrm{CI}$ $4.45-16.27) ; P<0.001)$ during the 27 -years of followup $[33,35]$.

Other studies have also suggested the beneficial effects of early glycaemic control in preventing future complications [36, 37]. Therefore, it appears that maintaining lower $\mathrm{HbAl}_{\mathrm{c}}$ levels in the early years after diagnosis may be beneficial in adults for reducing future risk of complications, regardless of subsequent glycaemic control over the course of diabetes duration. Diabetologists use the term "metabolic memory" for these observations. However, the DCCT contained only 195 adolescents (13 to 17 years of age at entry), with T1D duration of $38 \pm$ 20 months at the start of the trial [38]. Hence, the effect of insulin intensification from or near to diagnosis has not been robustly assessed in childhood-onset T1D. It would be important to note that adult outcomes cannot be extrapolated to childhood due to important biological and psychosocial determinants such as puberty, insulin resistance and adolescent risk-taking behaviours that are less relevant in adults [39].

Furthermore, some reports indicate that very early $\mathrm{HbA1}_{\mathrm{c}}$ level track with future glycemic control, i.e. low or high $\mathrm{HbA} 1_{\mathrm{c}}$ levels within the first few months of diagnosis associate with low or high $\mathrm{HbA1}_{\mathrm{c}}$ levels in later years, an effect which can persist for almost a decade [31, 40-43]. These studies were from USA and Europe, but the age range, duration of T1D, treatment and follow-up varied across studies. Additionally, the use of intensive insulin therapy in early childhood T1D is increasing but is not universal [44]. Also, many well-documented population-based registries lack robust and comparable data on glycemic control [45].

Our review will investigate whether $\mathrm{HbA} 1_{\mathrm{c}}$ levels in the first 2 years following diagnosis of T1D in children predicts future risk of complications and will quantify the extent to which the level of glycaemia in the first 2 years of diabetes tracks in adulthood/with increasing 
diabetes duration. We will also investigate the predictors of early glycaemic control and how these may influence the paediatric TID management plan. Our analyses may highlight a need for a change in early care processes in children with T1D, by providing an argument for more intensive diabetes treatments than are currently undertaken.

\section{Methods/study design}

We will undertake two linked systematic reviews answering two main research questions, namely:

1. Is higher early $\mathrm{HbAl}_{\mathrm{c}}$ (within 2 years of T1D diagnosis) associated with later complications in child-onset T1D patients (childhood-onset T1D defined as onset $\leq 18$ years)?

2. What factors at diagnosis or soon after are associated with higher early $\mathrm{HbAl}_{\mathrm{c}}$ ?

We will follow the methods for conducting systematic reviews, as described by the Evidence for Policy and Practice Information (EPPI) and Co-ordinating Centre [46]. The review process will be in four phases. Phase 1 (completed): iterative scoping stage to define the research question, refine the search strategy and outline the inclusion/exclusion and quality assessment criteria. This was followed by identification of literature by searching of electronic databases. Phase 2: descriptive mapping and synthesis of existing evidence by number, types and quality attributes of research studies on the topic. Phase 3: detailed data extraction and in-depth synthesis of quantitative studies [47]. Phase 4: thematic analysis of qualitative literature [48], followed by integration of these findings with the quantitative evidence by using parallel synthesis or mixed method approach [49]. This methodology of using qualitative research to explain quantitative evidence will provide a deeper understanding of the predictors influencing early glycaemic control in children and young people.

\section{Search strategy}

After a number of initial iterative scoping searches, with input from experts in the field, the search strategy was refined to maximise sensitivity and specificity in capturing key publications. Three sets of search terms were used (see search strategy in Table 1) relating to population (children and young people diagnosed with TID), exposure (terms to capture observational, intervention, qualitative studies and review articles relating to early diabetes control) and outcome (complications, mortality or metabolic memory).

Six electronic databases (Medline and Embase (via OVID), Web of Science (via Thomson Reuters), Cinhal (via EBSCO), Scopus (via Elsevier) and Cochrane Library) were double-searched in parallel (by VMP and HC to minimise study selection bias) in December 2014, without time period or language restrictions, by using a combination of free text and Thesaurus or Mesh terms (see Additional file 1: Electronic database search strategy.pdf). All identified articles from individual databases (Medline, $n=13,039$; Embase, $n=645$; Web of Science, $n=2323$; Cinahl, $n=984$; Scopus, $n=1540$ and Cochrane, $n=3242$ ) were imported into an endnote file and de-duplicated, which resulted in

Table 1 Search strategy for research questions: Does early glycaemic control (intervention within two years post diagnosis) in childhood-onset T1D have an impact on subsequent risk of complications in childhood and adulthood? What are the predictors of early glycaemic control?

\begin{tabular}{|c|c|c|}
\hline Population & Exposure & Outcome \\
\hline $\begin{array}{l}\text { Childhood or paediatric onset diabetes or } \\
\text { juvenile diabetes diagnosis or newly diagnosed } \\
\text { children or young persons or young people or } \\
\text { children or young or adolescent or teen or } \\
\text { youth or adult T1D patient or type } 1 \text { diabetes or } \\
\text { T1D or type } 1 \text { diabetes mellitus or T1DM or } \\
\text { DM1 or type } 1 \text { or IDDM or insulin dependent or } \\
\text { non-insulin dependent or childhood onset diabetes } \\
\text { or childhood onset T1D or auto-immune or } \\
\text { autoimmune or sudden onset or uncontrolled } \\
\text { or labile or brittle }\end{array}$ & $\begin{array}{l}\text { Early diabetes control or HbA1c trajectories or } \\
\mathrm{HbA} 1 \mathrm{c} \text { trends or glycaemic trajectories or } \\
\text { glycosylated or HbA1c or A1c or Hemoglobin A } \\
\text { or } \mathrm{HbA}(1 \mathrm{c}) \text { level or glycaemic control or glucose } \\
\text { control or diabetes control or early intensive } \\
\text { intervention or intensive or conventional or } \\
\text { standard or regular or optimised or tight control } \\
\text { or strict control or usual or routine or therapy or } \\
\text { treatment or intervention or management or } \\
\text { insulin use or injection or dose insulin injections } \\
\text { or intensive therapy or insulin pump }\end{array}$ & $\begin{array}{l}\text { Diabetic or diabetes complications or } \\
\text { complications or side effects or adverse events } \\
\text { or acute complications or chronic complications } \\
\text { or glycaemia or hyper glycaemia or hypo } \\
\text { glycaemia or ketosis or diabetic ketoacidosis or } \\
\text { DKA or nonketotic hyperosmolar coma or } \\
\text { insulin resistance or autoimmune disease or } \\
\text { urine albumin or urine albumin creatinine ratio } \\
\text { or urine albumin excretion or microalbuminuria } \\
\text { or macroalbuminuria or renal disease or diabetic } \\
\text { nephropathy or nephropathy or dialysis or foot } \\
\text { ulcer or amputation or retinopathy or blindness } \\
\text { or vascular disease or vascular complications or } \\
\text { microvascular disease or microvascular } \\
\text { complications or macrovascular disease or } \\
\text { macrovascular complications or cardiovascular } \\
\text { disease or Ml or myocardial infarction or stroke } \\
\text { or coronary artery disease or cerebrovascular } \\
\text { disease or peripheral vascular disease or blood } \\
\text { pressure or BP or statin or death or mortality or } \\
\text { Pathology or metabolism or metabolic memory }\end{array}$ \\
\hline
\end{tabular}


17,915 articles for further review. This will be supplemented by hand-searching reference lists and contacting authors of included studies and relevant reviews (see Fig. 1 for a flow diagram of the study selection process).

\section{Inclusion and exclusion criteria}

Interventional studies, i.e. randomised control trials (RCTs) and non-RCTs, targeting glycaemic control (within 2 years of diagnosis of T1D in children and young people) and describing an association with health outcomes will be included. Observational, i.e. cohort and cross-sectional studies that quantified the association between early glycaemic control (within 2 years of diagnosis of T1D) AND risk of future complications in children and young people aged 0 to 25 years at baseline, will be included. Qualitative studies that give a deeper background understanding on the predictors of early $\mathrm{HbA} 1_{c}$ in this age group will also be included.

Our exclusion criteria are as follows: non-human or animal studies, studies with population selected for other diseases/co-morbidities or clinical conditions, studies in adults aged more than 25 years at baseline, studies in other types of diabetes such as type 2 diabetes (T2D) or gestational diabetes. Quantitative studies not reporting clinical outcomes or quantitative studies that measured glycaemic control but did not describe an association with outcome variables will also be excluded. The overlapping eligibility criteria for the reviews are presented as inclusion/exclusion criteria in Table 2.

\section{Study selection procedure}

A $10 \%$ proportion (1792) of the total abstracts and titles will be randomly selected and double screened (DC and VMP), based on a piloted screening protocol. Results will be compared to ensure less than $5 \%$ discrepancy between reviewers. Any disagreements will be resolved through discussion and re-examining of abstract. Following which, all 17,915 abstracts and titles will be screened independently (VMP). Full texts of abstracts appearing to meet the inclusion criteria will be ordered for further review and data extraction. Descriptive mapping of existing evidence will be undertaken to establish gaps in evidence-base and to ascertain that there is sufficient data meriting review.

\section{Data extraction and quality assessment}

A data extraction Excel spread sheet will be piloted to ensure consistency of data extraction between reviewers. One of the reviewers (VMP) will then systematically review and extract detailed data of all studies meeting the

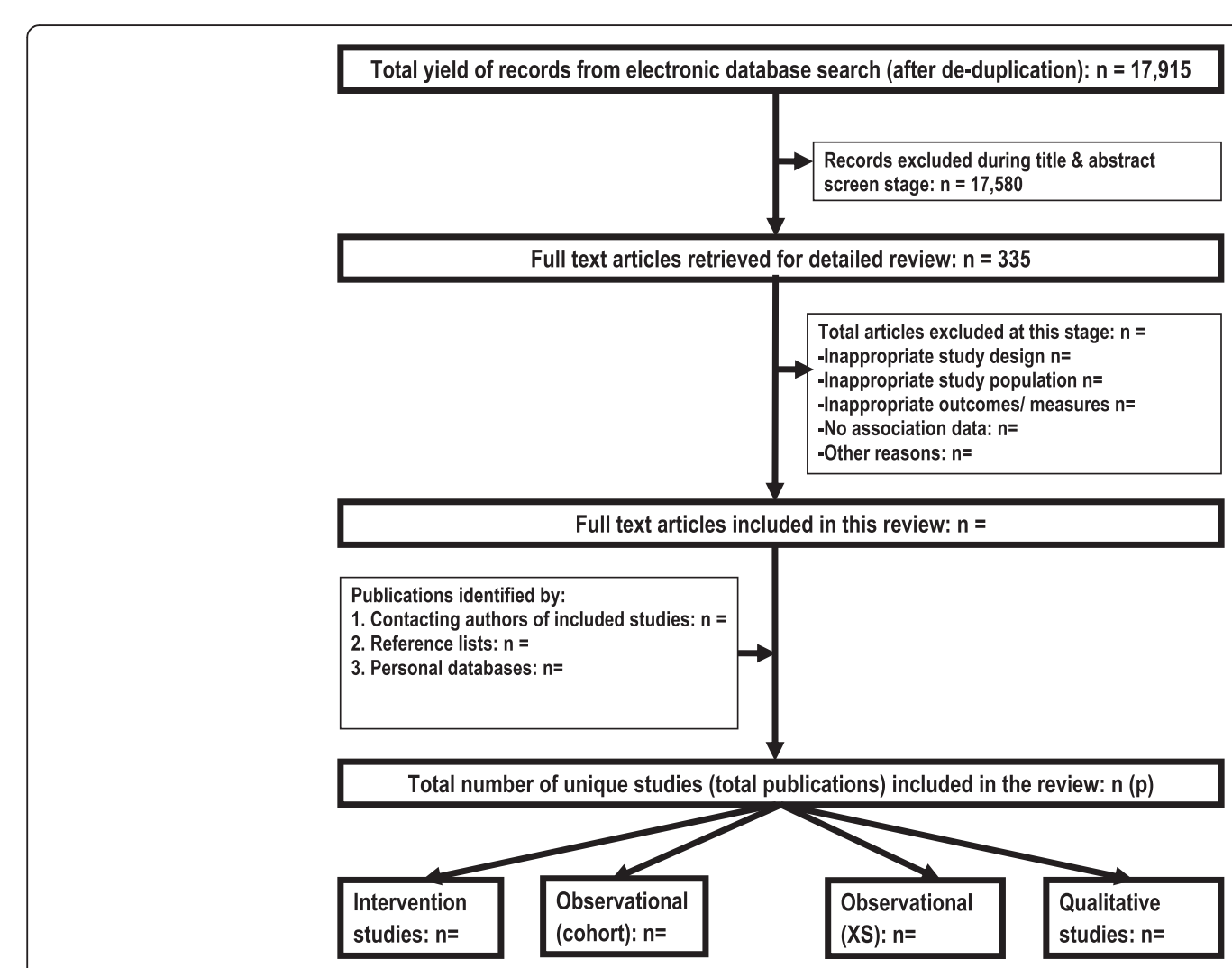

Fig. 1 Flowchart presenting an overview of the search results 
Table 2 Inclusion and exclusion criteria for review of evidence on the following: 1. Does early HbA1c predict later complications? 2. What factors predict early $\mathrm{HbA} 1 \mathrm{c}$ ?

\begin{tabular}{ll}
\hline Inclusion criteria & Exclusion criteria \\
\hline For reviews 1 and 2 & \\
$\begin{array}{ll}\text { Interventional studies (RCT's and non-RCT's) targeting glycaemic control (within } & \text { Non-human studies } \\
2 \text { years of diagnosis of T1D) and described an association with health outcomes } & \text { Selection of population based on other diseases/co-morbidities } \\
& \text { Adults aged more than 25 years at baseline } \\
& \text { Studies on T2D } \\
& \text { Quantitative studies not reporting clinical outcomes } \\
& \text { Quantitative studies that measured glycaemic control but did not } \\
\text { describe an association with outcome variables }\end{array}$
\end{tabular}

Non-intervention/observational, i.e. cohort and cross-sectional (XS) studies that quantified the association between early glycaemic control (within 2 years of diagnosis of T1D) AND risk of future complications in children and young people aged 0 to 25 years at baseline

For review 1: longitudinal studies with a follow-up of $\geq 5$ years from diagnosis

For review 2: qualitative studies that give a deeper background understanding on the topic

inclusion criteria. A proportion of the studies will be double-reviewed by a second reviewer, and any differences will be discussed and resolved. Details of data will be extracted according to study designs, i.e. interventional, observational and qualitative (see Table 3).

Included studies will be systematically quality-assessed against pre-set quality criteria by using standard quality assessment checklists designed by the EPPI centre for specific (intervention, observational and qualitative) study designs (see Table 4).

\section{Data syntheses}

Extracted data will be analysed and synthesised using a narrative and either forest plots or harvest plots (for quantitative evidence) and thematic analyses (for qualitative studies). To get a deeper understanding of the predictors of early glycaemic control in reducing complications in childhood and adult life, we will integrate qualitative and quantitative evidence using mixed methods or parallel synthesis approach.

\section{Intervention studies}

Meta analyses will be attempted to synthesise data from RCTs and Non-RCTs, assessed with low risk of bias and the results presented as forest plots [50]. Subgroup analyses by intervention type will be undertaken, subject to data type and quality.

\section{Observational studies}

Harvest plots [51] will be used to summarise data if meta-analysis/meta-regression is not possible. The evidence will be presented as bar charts and symbols. Colour (black, dark grey and light grey) of bar will represent quality of study, with lighter bars representing studies of low quality. Height of bar will indicate the study size, and position of the bar will summarise the direction and strength of the association $(++,+, 0,-,--)$. Categorical and continuous outcome variable results will be consistently recoded, such that a single or double + symbolises higher risk for complications, and a single or double symbolises a lower risk for complications [52, 53].

\section{Qualitative studies}

Evidence from qualitative studies will be synthesised thematically, and the results will be integrated with the quantitative evidence using the parallel synthesis or mixed methods approach [54, 55]. Recommendations for future interventions and policy decisions will be drawn by interpreting quantitative findings, using the themes identified from qualitative studies.

\section{Discussion}

The importance of diabetes-related complications may be underestimated. Data from the 2010-2011 National Paediatric Diabetes Audit (NPDA) showed that only $5.8 \%$ of all children and young persons with diabetes are recorded as having received all the National Institute for Health and Care Excellence (NICE) recommended care processes aimed at reducing risk of chronic complications [56]. This percentage increased to $16.1 \%$ in the 2013-2014 NPDA, which may reflect the incentivising effect of the recent introduction of the best practice tariff for paediatric diabetes care in the UK [57]. However, this percentage of optimum service delivery still compares 
Table 3 Details of data extracted for different study designs

\begin{tabular}{|c|c|c|}
\hline Intervention studies & $\begin{array}{l}\text { Observational/non-intervention studies } \\
\text { (cross-sectional and prospective) }\end{array}$ & Qualitative studies \\
\hline Study id & Study id & Study id \\
\hline Author & Author & Author \\
\hline Year & Year & Year \\
\hline Country & Country & Country \\
\hline Age range & Age range & Age \\
\hline Average age & Average age & Design \\
\hline Sex (male to female ratio) & Sex (male to female ratio) & $\begin{array}{l}\text { Number of } \\
\text { participants }\end{array}$ \\
\hline Design: $C R C T, R C T$, quasiRCT, before-after, etc. & Ethnicity & Sample/recruitment \\
\hline Number of participants & Socioeconomic status & $\begin{array}{l}\text { Findings/direct } \\
\text { quotes }\end{array}$ \\
\hline $\begin{array}{l}\text { Sample/recruitment, e.g. general population representative sample or } \\
\text { specialist groups (deprivation, ethnicity, geography, etc.) }\end{array}$ & Design (cross-sectional/prospective) & Author conclusions \\
\hline Intervention details (pump/injection, duration, dosage) & Number of participants & Comments \\
\hline Control & $\begin{array}{l}\text { Sample/recruitment, e.g. general population } \\
\text { representative sample or specialist groups }\end{array}$ & Author email \\
\hline Setting (home, primary care, secondary care) & Exposure examined & \\
\hline Intervention provider & Measurement of exposure & \\
\hline Number of sites & Measurement conducted by Level of glycemic control & \\
\hline $\begin{array}{l}\text { Outcome (complications, metabolic memory—separate row for each } \\
\text { outcome investigated) }\end{array}$ & Setting (home, primary care, secondary care) & \\
\hline Measurement of outcome (objective) & $\begin{array}{l}\text { Outcome (complications, metabolic } \\
\text { memory - separate row for each outcome } \\
\text { investigated) }\end{array}$ & \\
\hline Analysis & Measurement of outcome (objective) & \\
\hline Effect-point estimate & Analysis & \\
\hline \multicolumn{3}{|l|}{ Effect-upper confidence interval } \\
\hline \multicolumn{3}{|l|}{ Effect—lower confidence interval } \\
\hline Follow-up duration & Effect & \\
\hline Comments & Author email & \\
\hline Author email & Comments & \\
\hline
\end{tabular}

unfavourably to adults with diabetes ( $>60 \%$ received all recommended care processes during the 2011-2012 and 2012-2013 National Diabetes Audits (NDA)) and is very low when compared internationally $[16,58]$.

In a clinic setting, aiming for tight glycaemic targets remains difficult to achieve, outside of a clinical trial. The mean $\mathrm{HbA}_{\mathrm{c}}$ level in the intensively treated group participating for more than 20 years ago in the DCCT was lower than the $\mathrm{HbA}_{\mathrm{c}}$ levels in most patients today $[59,60]$. The intensive group achieved $\mathrm{HbA} 1_{\mathrm{c}}$ levels of $7 \%$ on an average compared with $8.3 \%$ among more than 25,000 patients from 67 US centres in the T1D exchange [59], and this was achieved without modern advances in therapy, such as insulin analogues and continuous glucose monitors. Therefore, we need to understand the effect, predictors and trends of early glycaemic control on complications risk in childhood and adults.

Our second aim is to look at which factors predict early $\mathrm{HbA} 1_{\mathrm{c}}$. These could be factors across the whole biopsychosocial model. For example, there may be social factors (deprivation, ethnic), psychological factors (teenage behaviour, fear of hypoglycaemia), physiological factors (glycation index) as well as wider cultural factors (the family, school, clinic setting, etc.).

By systematically reviewing evidence on effect of glycaemic control within first 2 years of T1D diagnosis and tracking with increasing diabetes duration, this will help identify predictors of early glycaemic control and understand future risk for complications in the paediatric population. 
Table 4 Quality assessment criteria by study design

\begin{tabular}{|c|c|c|}
\hline For intervention studies & $\begin{array}{l}\text { For observational (prospective cohort and } \\
\text { cross-sectional) studies }\end{array}$ & For qualitative studies \\
\hline $\begin{array}{l}\text { Total quality assessment score (maximum of 8) was } \\
\text { derived for the fulfilment of following criteria: }\end{array}$ & $\begin{array}{l}\text { Total quality assessment score (maximum } \\
\text { of 6) was derived for the fulfilment of } \\
\text { following criteria: }\end{array}$ & $\begin{array}{l}\text { Total quality assessment score (maximum of } \\
\text { 12) was derived for the fulfilment of } \\
\text { following criteria: }\end{array}$ \\
\hline 1) Randomisation & 1) More than 50 participants analysed & 1) Research questions clearly stated \\
\hline 2) Effect of intervention reported for all outcomes & 2) Studies representing general population & $\begin{array}{l}\text { 2) Approach appropriate for the research } \\
\text { question }\end{array}$ \\
\hline 3) Pre-intervention data on all outcomes & 3) Prospective study design & 3) Qualitative approach clearly justified \\
\hline 4) Post-intervention data on all outcomes & 4) Adjusted/multivariate analysis & 4) Study context clearly described \\
\hline 5) Allocation concealment & 5) Objective measure of outcome & 5) Role of the researcher clearly described \\
\hline 6) Blinding & 6) Objective measure of exposure & 6) Sampling method clearly described \\
\hline 7) Objective measurement of outcome & & $\begin{array}{l}\text { 7) Sampling strategy appropriate for the } \\
\text { research question }\end{array}$ \\
\hline 8) Retention $>70 \%$ & & $\begin{array}{l}\text { 8) Method of data collection clearly } \\
\text { described }\end{array}$ \\
\hline \multirow{4}{*}{$\begin{array}{l}\text { Studies with small sample size }(n<50) \text { and no control } \\
\text { group were considered to provide lower quality evidence } \\
\text { and not scored }\end{array}$} & & 9) Data collection method appropriate \\
\hline & & 10) Method of analysis clearly described \\
\hline & & $\begin{array}{l}\text { 11) Analysis appropriate for the research } \\
\text { question }\end{array}$ \\
\hline & & $\begin{array}{l}\text { 12) Conclusions supported by sufficient } \\
\text { evidence }\end{array}$ \\
\hline
\end{tabular}

\section{How this review compares with previous reviews in children and young adults}

To our knowledge, this is the first review to robustly investigate evidence on the association of early glycaemic control in childhood-onset T1D with future complications risk. Furthermore, this is the first review to rigorously and systematically integrate quantitative (both intervention and observational) and qualitative evidence on this topic [55]. Evidence synthesised this way is holistic and more reliable than syntheses of any one type of research in isolation.

\section{Dissemination and updating plans}

Results of the review will be disseminated through peerreviewed publications, conference presentations and at meetings. The review will be updated if significant new evidence becomes available.

\section{Additional file}

Additional file 1: Electronic database search strategy.

\section{Abbreviations}

DCCT: Diabetes Control and Complications Trial; EPPI: Evidence for Policy and Practice Information; HbA1 $\mathrm{c}$ : glycated haemoglobin $\mathrm{A} 1_{c} ; \mathrm{NDA}$ : National Diabetes Audit; NICE: National Institute for Health and Care Excellence; NPDA: National Paediatric Diabetes Audit; PROSPERO: International Prospective Register for systematic Reviews; RCT: randomised control trial; T1D: type 1 diabetes.

\section{Competing interests}

No potential conflict of interest was reported by the authors.

\section{Authors' contributions}

VMP was the lead reviewer, created the study design and search strategy, searched electronic databases for literature and wrote the first draft of the protocol. RA conceptualised the project, was project lead, advised on the trajectories of the project, participated in the study design and helped revise the manuscript. DC double screened a proportion of titles/abstracts, participated in the study design and helped revise the manuscript. ARK participated in the design of the study and helped revise the manuscript. DTR participated in the design of the study and helped revise the manuscript. TS was overall project lead, advised on the trajectories of the project, participated in the study design and helped revise the manuscript. RV advised on the trajectories of the project, participated in the study design and helped revise the manuscript. JE advised on the trajectories of the project, participated in the study design and helped revise the manuscript. All authors contributed to the study design, critical revision of the manuscript and approved the final version.

\section{Acknowledgements}

Our sincere thanks to the funders and the following from the University College London: Miss Heather Chester $(\mathrm{HC})$ for her help with the literature search strategy and Mrs Linda Haines for her help and support throughout. The authors also thank the following collaborators for their comments and guidance on the project: Prof. David Dunger, Department of Paediatrics, University of Cambridge; Dr. Bob Young, consultant diabetologist and CMIO, Diabetes and Endocrinology, Salford Royal Foundation NHS Trust; clinical lead, National Diabetes Audit (NDA) and National Cardiovascular Intelligence Network (NCVIN), Dr. Alison Elderfield and project manager, National Paediatric Diabetes Audit Research and Policy Division; Royal College of Paediatrics and Child Health, Dr Justin Warner, consultant in Paediatric Endocrinology and Diabetes, honorary Senior Lecturer Cardiff University, and clinical lead for the National Paediatric Diabetes Audit; and Dr. Fiona Campbell, national clinical lead for the Children and Young People's Diabetes Network and Peer Review Quality Assurance Programme, NHS England. 


\section{Funding}

This project is funded by UCL IMPACT/Department of Health PhD Studentship 2014/15. This is an independent report commissioned and funded by the Policy Research Programme in the Department of Health. The views expressed are not necessarily those of the department.

\section{Author details}

${ }^{1}$ Institute of Child Health, University College London, London, UK. ${ }^{2}$ Institute of Public Health, University of Cambridge, Cambridge, UK. ${ }^{3}$ Institute of Environmental Medicine, Karolinska Institutet, Stockholm, Sweden. ${ }^{4}$ University of Liverpool, Liverpool, UK. ${ }^{5}$ Oxford Children's Hospital, University of Oxford, Oxford, UK.

\section{Received: 21 September 2015 Accepted: 27 October 2015}

Published online: 12 November 2015

\section{References}

1. Lind M, Svensson A, Kosiborod M, Gudbjörnsdottir S, Pivodic A, Wedel H, et al. Glycemic control and excess mortality in type 1 diabetes. N Engl J Med. 2014;371(21):1972-82

2. Livingstone SJ, Levin D, Looker HC, Lindsay RS, Wild SH, Joss N, et al. Estimated life expectancy in a Scottish cohort with type 1 diabetes, 2008-2010. JAMA. 2015;313(1):37-44.

3. Harjutsalo V, Forsblom C, Groop PH. Time trends in mortality in patients with type 1 diabetes: nationwide population based cohort study. BMJ. 2011;343:d5364

4. Patterson CC, Dahlquist G, Harjutsalo V, Joner G, Feltbower RG, Svensson J, et al. Early mortality in EURODIAB population-based cohorts of type 1 diabetes diagnosed in childhood since 1989. Diabetologia. 2007;50(12):2439-42.

5. Edge JA, Ford-Adams ME, Dunger DB. Causes of death in children with insulin dependent diabetes 1990-96. Arch Dis Child. 1999;81(4):318-23.

6. Fazeli Farsani S, Souverein PC, van der Vorst MM, Knibbe CA, de Boer A, Mantel-Teeuwisse AK. Chronic comorbidities in children with type 1 diabetes: a population-based cohort study. Arch Dis Child. 2015;100(8):763-8.

7. Froisland DH, Graue M, Markestad T, Skrivarhaug T, Wentzel-Larsen T, Dahl-Jorgensen K. Health-related quality of life among Norwegian children and adolescents with type 1 diabetes on intensive insulin treatment: a population-based study. Acta Paediatr. 2013;102(9):889-95.

8. Persson S, Dahlquist G, Gerdtham UG, Steen Carlsson K. Impact of childhood-onset type 1 diabetes on schooling: a population-based register study. Diabetologia. 2013;56(6):1254-62.

9. Chief Medical Officer's annual report 2012: Our Children Deserve Better: Prevention Pays 24 October 2013. Available from: https://www.gov.uk/ government/publications/chief-medical-officers-annual-report-2012-ourchildren-deserve-better-prevention-pays

10. Cameron FJ, de Beaufort C, Aanstoot HJ, Hoey H, Lange K, Castano L, et al. Lessons from the Hvidoere International Study Group on childhood diabetes: be dogmatic about outcome and flexible in approach. Pediatr Diabetes. 2013;14(7):473-80.

11. Tamayo T, Rosenbauer J, Wild SH, Spijkerman AM, Baan C, Forouhi NG, et al. Diabetes in Europe: an update. Diabetes Res Clin Pract. 2014:103(2):206-17.

12. Patterson C, Guariguata L, Dahlquist G, Soltesz G, Ogle G, Silink M. Diabetes in the young - a global view and worldwide estimates of numbers of children with type 1 diabetes. Diabetes Res Clin Pract. 2014;103(2):161-75.

13. Stanescu DE, Lord K, Lipman TH. The epidemiology of type 1 diabetes in children. Endocrinol Metab Clin North Am. 2012:41(4):679-94.

14. International Diabetes Federation. IDF diabetes atlas: 2013. https:// www.idf.org/diabetesatlas.

15. Harjutsalo V, Sjöberg L, Tuomilehto J. Time trends in the incidence of type 1 diabetes in Finnish children: a cohort study. Lancet. 2008;371(9626):1777-82.

16. DIAMOND. Incidence and trends of childhood type 1 diabetes worldwide 1990-1999. Diabet Med. 2006;23(8):857-66.

17. Patterson CC, Dahlquist GG, Gyurus E, Green A, Soltesz G. Incidence trends for childhood type 1 diabetes in Europe during 1989-2003 and predicted new cases 2005-20: a multicentre prospective registration study. Lancet. 2009;373(9680):2027-33

18. Kanavos P, van de Aardweg S, Schurer W. Diabetes expenditure, burden of disease and management in 5 EU countries. London: London School of Economics Health; 2012
19. DCCT. The effect of intensive treatment of diabetes on the development and progression of long-term complications in insulin-dependent diabetes mellitus. The Diabetes Control and Complications Trial Research Group. N Engl J Med. 1993;329(14):977-86.

20. Nordwall M, Arnqvist HJ, Bojestig M, Ludvigsson J. Good glycemic control remains crucial in prevention of late diabetic complications - the Linkoping Diabetes Complications Study. Pediatr Diabetes. 2009;10(3):168-76.

21. White NH, Sun W, Cleary PA, Tamborlane W, Danis RP, Hainsworth DP, et al. Effect of prior intensive therapy in type 1 diabetes on 10-year progression of retinopathy in the DCCT/EDIC: comparison of adults and adolescents. Diabetes. 2010;59(5):1244-53.

22. Hirose A, Furushima D, Yamaguchi N, Kitano S, Uchigata Y. Prediction of retinopathy at 20 years after onset in younger-onset type 1 diabetes using mean metabolic memory-free $\mathrm{HbA1c}$ values: the importance of using HbA1c data of total, not partial, diabetes duration. Diabetes Care. 2013;36(11):3812-4.

23. Johnson SR, Cooper MN, Jones TW, Davis EA. Long-term outcome of insulin pump therapy in children with type 1 diabetes assessed in a large population-based case-control study. Diabetologia. 2013;56(11):2392-400.

24. Kahler P, Grevstad B, Almdal T, Gluud C, Wetterslev J, Vaag A, et al. Targeting intensive versus conventional glycaemic control for type 1 diabetes mellitus: a systematic review with meta-analyses and trial sequential analyses of randomised clinical trials. BMJ Open. 2014;4(8):e004806.

25. Shah SC, Malone Jl, Simpson NE. A randomized trial of intensive insulin therapy in newly diagnosed insulin-dependent diabetes mellitus. N Engl J Med. 1989;320(9):550-4.

26. Hershey T, Bhargava N, Sadler M, White NH, Craft S. Conventional versus intensive diabetes therapy in children with type 1 diabetes: effects on memory and motor speed. Diabetes Care. 1999;22(8):1318-24.

27. Franklin VL, Khan F, Kennedy G, Belch JJ, Greene SA. Intensive insulin therapy improves endothelial function and microvascular reactivity in young people with type 1 diabetes. Diabetologia. 2008;51(2):353-60.

28. Perlman K, Ehrlich RM, Filler RM, Albisser AM. Sustained normoglycemia in newly diagnosed type I diabetic subjects. Short-term effects and one-year follow-up. Diabetes. 1984;33(10):995-1001.

29. Fullerton B, Jeitler K, Seitz M, Horvath K, Berghold A, Siebenhofer A. Intensive glucose control versus conventional glucose control for type 1 diabetes mellitus. Cochrane Database Syst Rev. 2014;2:Cd009122.

30. Wysocki T, Harris MA, Wilkinson K, Sadler M, Mauras N, White NH. Selfmanagement competence as a predictor of outcomes of intensive therapy or usual care in youth with type 1 diabetes. Diabetes Care. 2003;26(7):2043-7.

31. Orchard TJ, Nathan DM, Zinman B, Cleary P, Brillon D, Backlund JY, et al. Association between 7 years of intensive treatment of type 1 diabetes and long-term mortality. JAMA. 2015;313(1):45-53.

32. Tamborlane W, Beck RW, Bode BW, Buckingham B, Chase HP, Clemons R et al. Continuous glucose monitoring and intensive treatment of type 1 diabetes. N Engl J Med. 2008;359(14):1464-76.

33. Aiello LP. Diabetic retinopathy and other ocular findings in the diabetes control and complications trial/epidemiology of diabetes interventions and complications study. Diabetes Care. 2014;37(1):17-23.

34. Lachin JM, Orchard TJ, Nathan DM. Update on cardiovascular outcomes at 30 years of the diabetes control and complications trial/epidemiology of diabetes interventions and complications study. Diabetes Care. 2014;37(1):39-43.

35. Nathan DM, Bayless M, Cleary P, Genuth S, Gubitosi-Klug R, Lachin JM, et al. Diabetes control and complications trial/epidemiology of diabetes interventions and complications study at 30 years: advances and contributions. Diabetes. 2013;62(12):3976-86.

36. Cengiz E, Connor CG, Ruedy KJ, Beck RW, Kollman C, Klingensmith GJ, et al Pediatric diabetes consortium T1D new onset (NeOn) study: clinical outcomes during the first year following diagnosis. Pediatr Diabetes. 2014;15(4):287-93.

37. Nordwall M, Abrahamsson M, Dhir M, Fredrikson M, Ludvigsson J, Arnqvist $\mathrm{HJ}$. Impact of $\mathrm{HbA1c}$, followed from onset of type 1 diabetes, on the development of severe retinopathy and nephropathy: the VISS study (vascular diabetic complications in southeast Sweden). Diabetes Care. 2015;38(2):308-15.

38. Control DRGD, Complications Trial Research Group AclotDRGiafNTIS. Effect of intensive diabetes treatment on the development and progression of long-term complications in adolescents with insulin-dependent diabetes mellitus: diabetes control and complications trial. J Pediatr. 1994;125(2):177-88.

39. Lawes T, Franklin V, Farmer G. HbA1c tracking and bio-psychosocial determinants of glycaemic control in children and adolescents with type 1 
diabetes: retrospective cohort study and multilevel analysis. Pediatr Diabetes. 2014;15(5):372-83.

40. Dovc K, Telic SS, Lusa L, Bratanic N, Zerjav-Tansek M, Kotnik P, et al. Improved metabolic control in pediatric patients with type 1 diabetes: a nationwide prospective 12-year time trends analysis. Diabetes Technol Ther. 2014;16(1):33-40.

41. Samuelsson U, Steineck I, Gubbjornsdottir S. A high mean-HbA1c value 3-15 months after diagnosis of type 1 diabetes in childhood is related to metabolic control, macroalbuminuria, and retinopathy in early adulthood-a pilot study using two nation-wide population based quality registries. Pediatr Diabetes. 2014;15(3):229-35.

42. Edge JA, James T, Shine B. Persistent individual tracking within overall improvement in $\mathrm{HbA} 1 \mathrm{C}$ in a UK paediatric diabetes clinic over 15 years. Diabet Med. 2010;27(11):1284-8.

43. Gerstl EM, Rabl W, Rosenbauer J, Grobe H, Hofer SE, Krause U, et al. Metabolic control as reflected by HbA1c in children, adolescents and young adults with type-1 diabetes mellitus: combined longitudinal analysis including 27,035 patients from 207 centers in Germany and Austria during the last decade. Eur J Pediatr. 2008;167(4):447-53.

44. National Paediatric Diabetes Audit Report 2011-12: Royal College of Paediatrics and Child Health; 2013. Available from: http://www.hqip.org.uk/ assets/NCAPOP-Library/NCAPOP-2013-14/NPDA-report-2011-12-low-resFINAL.pdf.

45. Livingstone SJ, Looker HC, Hothersall EJ, Wild SH, Lindsay RS, Chalmers J, et al. Risk of cardiovascular disease and total mortality in adults with type diabetes: Scottish registry linkage study. PLoS Med. 2012;9(10):e1001321.

46. Evidence for Policy and Practice Information (EPPI) and Co-ordinating Centre loE, University of London. EPPI-Centre Methods for Conducting Systematic Reviews. March 2007, Updated 2010: http://eppi.ioe.ac.uk/cms/ LinkClick.aspx?fileticket=hQBu8y4uVwl\%3d.

47. Mazarello Paes V, Hesketh K, O'Malley C, Moore H, Summerbell C, Griffin S, et al. Determinants of sugar-sweetened beverage consumption in young children: a systematic review. Obes Rev. 2015;16(11):903-13.

48. Mazarello Paes V, Ong KK, Lakshman R. Factors influencing obesogenic dietary intake in young children (0-6 years): systematic review of qualitative evidence. BMJ Open. 2015;5(9):e007396.

49. Shaw RL, Larkin M, Flowers P. Expanding the evidence within evidencebased healthcare: thinking about the context, acceptability and feasibility of interventions. Evid Based Med. 2014;19(6):201-3.

50. Pace NL. Research methods for meta-analyses. Best Pract Res Clin Anaesthesiol. 2011;25(4):523-33.

51. Ogilvie D, Fayter D, Petticrew M, Sowden A, Thomas S, Whitehead M, et al The harvest plot: a method for synthesising evidence about the differential effects of interventions. BMC Med Res Methodol. 2008:8:8.

52. Lakshman R, Mazarello Paes V, Hesketh K, O'Malley C, Moore H, Ong K, et al. Protocol for systematic reviews of determinants/correlates of obesity-related dietary and physical activity behaviors in young children (preschool 0 to 6 years): evidence mapping and syntheses. Syst Rev. 2013;2:28.

53. Wijndaele K, Lakshman R, Landsbaugh JR, Ong KK, Ogilvie D. Determinants of early weaning and use of unmodified cow's milk in infants: a systematic review. J Am Diet Assoc. 2009;109(12):2017-28

54. Barnett I, Guell C, Ogilvie D. The experience of physical activity and the transition to retirement: a systematic review and integrative synthesis of qualitative and quantitative evidence. Int J Behav Nutrit Phys Act. 2012;9:97.

55. Thomas J, Harden A, Oakley A, Oliver S, Sutcliffe K, Rees R, et al. Integrating qualitative research with trials in systematic reviews. BMJ. 2004;328(7446):1010-2.

56. National Paediatric Diabetes Audit Report 2010-11: Royal College of Paediatrics and Child Health; 2012. Available from: http://www.rcpch.ac.uk/ system/files/protected/page/NPDA\%20Annual\%20Report_25\%2009\% 2012\%20for\%20web_0.pdf.

57. National Paediatric Diabetes Audit Report 2013-14: Royal College of Paediatrics and Child Health; 2015. Available from: http://www.rcpch.ac.uk/ system/files/protected/page/Revised\%20Sept\%202014\%20NPDA\%20 Report\%201\%20FINAL.pdf.

58. National Paediatric Diabetes Audit Report 2012-13: Part 1; Care processes and outcomes: Royal College of Paediatrics and Child Health. 2014. Available from: http://www.rcpch.ac.uk/system/files/protected/page/ NPDA\%202012-13\%20Core\%20Report\%202nd\%20FINAL\%20v\%203.3.pdf.
59. Beck RW, Tamborlane WW, Bergenstal RM, Miller KM, DuBose SN, Hall CA, et al. The T1D exchange clinic registry. J Clin Endocrinol Metab. 2012;97(12):4383-9.

60. Ali MK, Bullard KM, Saaddine JB, Cowie CC, Imperatore G, Gregg EW. Achievement of goals in U.S. diabetes care, 1999-2010. N Engl J Med. 2013;368(17):1613-24.

\section{Submit your next manuscript to BioMed Central and take full advantage of:}

- Convenient online submission

- Thorough peer review

- No space constraints or color figure charges

- Immediate publication on acceptance

- Inclusion in PubMed, CAS, Scopus and Google Scholar

- Research which is freely available for redistribution 